\title{
PIJAT REFLEKSI BERPENGARUH TERHADAP TEKANAN DARAH PADA PASIEN HIPERTENSI DI KLINIK ATGF 8 PALEMBANG
}

\author{
Lukman*, Sumitro Adi Putra, Elba Habiburrahma, Sukma Wicaturatmashudi, \\ Rumentalia Sulistini, Ismar Agustin
}

\author{
Jurusan Keperawatan Politeknik Kesehatan Kemenkes Palembang
}

*Korespondensi penulis: lukman@poltekkespalembang.ac.id

\begin{abstract}
ABSTRAK
Latarbelakang: Hipertensi sering disebut sebagai pembunuh yang tidak diketahui, karena penderita tidak tahu bahwa dirinya menderita hipertensi. Banyak macam terapi komplementer yang dapat diterapkan untuk mengobati hipertensi, salah satunya pijat refleksi.

Metode: Penelitian ini bertujuan untuk mengetahui pengaruh pijat refleksi terhadap tekanan darah pada pasien hipertensi di Klinik ATFG-8 Palembang. Desain yang digunakan pada penelitian ini adalah pra-eksperimen dengan menggunakan rancangan one group pre-test post-test. Sampel pada penelitian ini adalah keseluruhan pasien hipertensi yang tidak mengkonsumsi obat penurun tekanan darah dan berkunjung untuk melakukan terapi pijat refleksi pada bulan 17 April s.d 17 Mei 2018. Penentuan sampel dengan metode purposive sampling sebanyak 18 subjek penelitian.

Hasil: Hasil yang diperoleh adalah rata-rata usia sampel 54,22 tahun $( \pm 7,216)$, tekanan darah sistolik sebelum 148,44 $\mathrm{mmHg}( \pm 4,527)$ dan setelah pijat refleksi $143,78 \mathrm{mmHg}( \pm 8,633)$. Hasil paired sample T test menunjukkan efek pijat refleksi pada tekanan darah sistolik $(\mathrm{p}=0,026)$ dan diastolik $(\mathrm{p}=0,001)$

Kesimpulan: Terjadi penurunan tekanan darah secara statistik, namun secara substansi tidak bermakna. Peneliti berikutnya diharapkan untuk melakukan penelitian lebih lanjut dengan menambahkan sampel dan menggunakan kelompok kontrol.
\end{abstract}

Kata Kunci: hipertensi; pasien; pijat reflesi; tekanan darah.

\section{REFLEXOLOGY MASSSAGE IS AFFECTING THE BLOOD PRESSURE ON HYPERTENTION PATIENTS AT ATGF 8 CLINIC OF PALEMBANG}

\section{ABSTRACT}

Background: Hypertension is often referred to as an unknown killer, because patients do not know that they suffer from hypertension. Many types of complementary therapies that can be applied to treat hypertensive patients, one of which is reflexology

Method: This study aims to determine the effect of reflection on blood pressure in hypertensive patients at the Palembang ATFG-8 clinic. The design used in this study was pre-experimental using one group pre-test post-test design. The sample in this study were all hypertensive patients who visited for reflexology in April 17 until May 17, 2018. Determination of the sample using a purposive sampling method totaling 18 subjects.

Result: The results obtained were the average age of the sample 54.22 years ( \pm 7.216$)$, systolic blood pressure before $148.44 \mathrm{mmHg}( \pm 4,527)$ and after reflexology $143.78 \mathrm{mmHg}( \pm 8,633)$. Diastolic blood pressure before $95.72 \mathrm{mmHg}( \pm$ $2.886)$ and after reflexology $91.06 \mathrm{mmHg}( \pm 5,252)$. The paired sample $T$ test results showed the effect of reflexology on systolic blood pressure $(p=0.026)$ and diastolic $(p=0.001)$.

Conclusion : There was a decrease in blood pressure statistically, but in substance it was not significant. The next researcher is expected to carry out further research by adding samples and using a control group.

Key Words: hypertension; patients; reflexology; blood pressure 


\section{PENDAHULUAN}

Hipertensi adalah suatu keadaan kronis yang ditandai dengan meningkatnya tekanan darah pada dinding pembuluh darah arteri. Seseorang dikatakan mengalami hipertensi jika pemeriksaan tekanan darah menunjukkan hasil di atas 140/90 $\mathrm{mmHg}$ atau lebih dalam keadaan istirahat, dengan dua kali pemeriksaan, dan selang waktu lima menit. ${ }^{1}$ Apabila tekanan darah $\geq$ 140/90 mmHg pada dua atau lebih kunjungan, hipertensi dapat ditegakkan. ${ }^{2}$

Hipertensi sering disebut sebagai the silent killer karena penderita tidak tahu bahwa dirinya menderita hipertensi. Hipertensi juga merupakan faktor resiko ketiga terbesar yang menyebabkan kematian dini karena dapat memicu terjadinya gagal jantung kongestif serta penyakit cerebrovaskuler. $^{3}$

Amerika Serikat menjadi negara dengan angka hipertensi paling tinggi. Sekitar 25.000 kematian dan lebih dari 1,5 juta serangan jantung dan stroke terjadi setiap tahun. ${ }^{4}$ Diperkirakan sekitar 80\% kenaikan kasus hipertensi terutama terjadi di negara berkembang pada tahun 2025, dari jumlah 639 juta kasus di tahun 2000. Jumlah ini diperkirakan meningkat menjadi 1,15 miliar kasus di tahun 2025. ${ }^{5}$ Hipertensi di Indonesia merupakan masalah kesehatan dengan prevalensi yang tinggi yaitu sebesar 28,5\%. Prevalensi tertinggi di Bangka Belitung (30,9\%), diikuti Kalimantan Selatan (30,8\%), Kalimantan Timur $(29,6 \%)$, Jawa Barat $(29,4 \%)$, dan Gorontalo $(29,4 \%)$.

Jumlah penderita hipertensi di Sumatera Selatan pada tahun 2013 sebanyak 183.048 jiwa, pada tahun 2014 sebanyak 186.116 jiwa, pada tahun 2015 sebanyak 204.213 jiwa, pada tahun 2016 sebanyak 225.305 jiwa dan pada tahun 2017 sebanyak 229.365 jiwa. $^{7}$

Pengobatan hipertensi dilakukan dengan dua cara, yaitu pengobatan secara nonfarmakologis dan farmakologis. Pengobatan farmakologis dengan meminum obat antihipertensi. Pengobatan non farmakologis yaitu lebih menekankan pada perubahan pola makan dan gaya hidup seperti mengurangi konsumsi garam, mengendalikan berat badan, mengendalikan minum kopi, membatasi konsumsi lemak, berolahraga secara teratur, menghindari stress, terapi komplementer (terapi herbal, terapi nutrisi, relaksasi progresif, meditasi, akupuntur, akupresur, aromaterapi, refleksiologi, dan bekam. ${ }^{8}$ Pijat refleksi menjadi pilihan karena tindakan ini aman bagi pasien karena bukan tindakan invasif dan mudah dilakukan oleh trafis.

Pijat refleksi memberikan rangsangan berupa tekanan pada syaraf tubuh manusia
Biasanya, pemijatan akan memberikan tekanan pada titik tangan atau kaki. Rangangan tersebut diterima oleh reseptor saraf (saraf penerima rangsangan). Rangsangan yang diterima ini akan diubah oleh tubuh menjadi "aliran listrik". Aliran tersebut kemudian akan menjalar ke sumsum tulang belakang. Dari sumsum tulang belakang akan diteruskan ke bagian otak dan otot. Pijat refleksi membantu mengurangi gejala penyakit lever, ginjal, jantung, tekanan darah tinggi, dan hampir semua penyakit yang dikenal manusia. ${ }^{9}$

Cara kerja refleksiologi sama seperti akupuntur, akupresur, dan shiatsu dalam menormalkan keseimbangan aliran energi vital (chi) pada titik-titik meridian. Kebanyakan praktisi terapi refleksiologi memfokuskan zona refleksi pada kaki, walaupun zona-zona yang lain pun bisa di sentuh seperti tangan dan telinga. ${ }^{10}$ Rahimsyah $^{11}$ dalam bukunya mengatakan letak daerah refleksi selain ditelapak tangan dan telapak kaki terdapat tambahan titik refleksi di bagian tubuh depan, belakang dan wajah. Pijat refleksi adalah salah satu bentuk pengobatan komplementer dan alternatif terbaik di Inggris dan digunakan untuk perawatan kesehatan oleh beragam orang. Faktanya complementary alternative medicine (CAM) semakin dianggap sebagai cara yang aman dan efektif untuk mengurangi penyebab dan dampak rasa sakit dan penyakit. ${ }^{12}$ Pijat refleksi adalah salah satu dari enam bentuk CAM terbaik yang digunakan di Inggris. ${ }^{13}$

Terapi ini bukan untuk mengobati pengobatan konvensional (kedokteran), melainkan sebagai pelengkap untuk mengontrol tekanan darah. ${ }^{8}$ Berdasarkan beberapa latar belakang di atas, peneliti tertarik melakukan penelitian untuk mengetahui efek pijat refleksi pada telapak kaki terhadap tekanan darah pada pasien hipertensi.

\section{METODE}

Penelitian ini menggunakan desain Praeksperimen dengan rancangan one group pretest posttest design. Populasi dalam penelitian ini adalah keseluruhan pasien hipertensi yang berkunjung yang berjumlah 28 orang untuk melakukan terapi pijat refleksi di Klinik ATFG-8 Palembang pada tanggal 17 April s.d 17 Mei Maret 2018. Besar sampel minimal dihitung menggunakan rumus Lameshow ${ }^{14}$, yang mendapatkan 18 orang. Sampel diambil dengan menggunakan teknik purposive sampling dan memenuhi kriteria inklusi: bersedia menjadi responden, bersedia mengikuti prosedur penelitian sampai selesai, didiagnosis menderita 
hipertensi (tekanan darah sistol $>140 \mathrm{mmHg}$ dan tekanan darah diastol $>90 \mathrm{mmHg}$ ) oleh dokter, tidak minum obat penurun tekanan darah dan mampu berkomunikasi dengan baik. Pengukuran tekanan darah sebelum tindakan pijat refleksi menggunakan tensimeter digital, yang dilakukan oleh seorang enumerator setelah responden mengisi informed consent dan data karakteristik diperoleh, sekitar 15 menit sejak kedatangan. Pengukuran tekanan darah setelah pijat refleksi dilakukan sesat setelah tindakan pijat refleski yang dilakukan oleh terapis.

Instrumen penelitian yang digunakan pada penelitian ini adalah catatan kunjungan pasien dan lembar observasi yang berisi informasi karakteristik subyek berupa nama, usia, jenis kelamin, lamanya menderita hipertensi, tekanan darah sebelum dan sesudah tindakan pijat refleksi. Untuk pengukuran tekanan darah, menggunakan adalah tensimeter digital.

Peneliti atau enumerator memilih sampel yang memenuhi syarat setelah mendapatkan izin dari tempat penelitian yang sebelumnya sudah diberikan petunjuk dan latihan, dilanjutkan dengan informed consent. Pengukuran tekanan darah sebelum tindakan pijat refleksi dilakukan setelah data karakteristik lengkap. Terapis melakukan pemijatan kepada subyek pada titiktitik pijat refleksi selama 60 menit sebanyak satu kali perlakuan. Tekanan darah diukur sesaat setelah tindakan pijat refleksi.

Data yang diperoleh dianalisis secara deskriptif berupa mean, median, SD, minimum maksimum dan dan disajikan dalam bentuk numerik. Uji normalitas data menggunakan uji Shapiro-Wilk karena jumlah subyek kurang 50. Uji t berpasangan (paired t-test) dilakukan untuk menguji efek tindakan pijat refleksi.

\section{HASIL DAN PEMBAHASAN}

Hasil penelitian melibatkan 10 orang lakilaki dan 8 orang perempuan, pada tabel 1 dipaparkan bahwa rerata usia responden 54,22 ( \pm $7,216)$ dengan rerata lama menderita hipertensi $3,78( \pm 1,865)$ tahun.

Rerata tekanan darah sistolik sebelum dan setelah tindakan pijat refleksi berturut-turut $148,44( \pm 4,527)$ dan $143,50( \pm 8,633)$. Sementara rerata tekanan darah diastolik sebelum dan setelah adalah 95,72 $( \pm 2,886)$ dan 91,06 $( \pm 5,252)$ (Tabel 2).

Berdasarkan tabel 3, ada perbedaan tekanan darah sebelum dan setelah pijat refleksi baik pada tekanan darah sistolik maupun diastolik. Sehingga didapatkan, ada pengaruh tindakan pijat refleksi terhadap tekanan darah sistolik $(p=0,026)$ dan tekanan darah diastolik $(p=0,001)$.

Tabel 1. Karakteristik Responden $(n=18)$

\begin{tabular}{lllll}
\hline Karakteristik & Mean & Median & SD & Max-Min \\
\hline Usia & 54,22 & 56 & 7,216 & $39-66$ \\
\hline Lama & & & & \\
$\begin{array}{l}\text { Menderita } \\
\text { Hipertensi }\end{array}$ & 3,78 & 3,00 & 1,865 & $1-8$ \\
\hline
\end{tabular}

Tabel 2. Tekanan Darah Sebelum dan Setelah Pijat Refleksi $(n=18)$

\begin{tabular}{|c|c|c|c|c|}
\hline Tekanan Darah & Mean & Median & SD & Max-Min \\
\hline Sistolik & & & & \\
\hline Sebelum pijat refleksi & 148,44 & 148,00 & 4,527 & $142-157$ \\
\hline Setelah pijat refleksi & 143,50 & 145,50 & 8,633 & $127-157$ \\
\hline \multicolumn{5}{|l|}{ Diastolik } \\
\hline Sebelum pijat refleksi & 95,72 & 96,00 & 2,886 & $92-100$ \\
\hline Setelah pijat refleksi & 91,06 & 92,00 & 5,252 & $82-102$ \\
\hline
\end{tabular}

Tabel 3. Perbedaan Tekanan Darah Sebelum dan Setelah Pijat Refleksi $(n=18)$

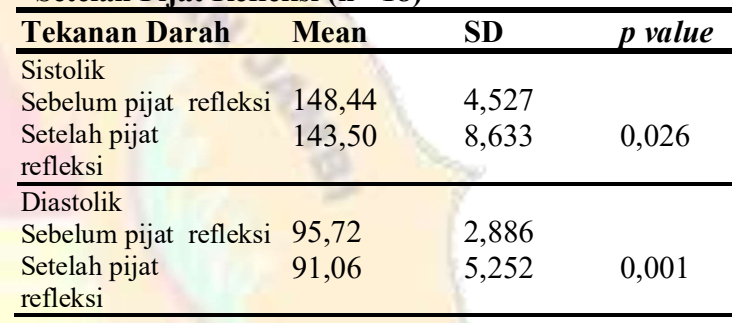

Hasil penelitian ini menunjukkan tindakan pijat refleksi kaki berpengaruh terhadap tekanan darah baik sistolik dan diastolik pada pasien hipertensi. Hasil tersebut mendukung penelitian yang menerangkan bahwa terapi pijat refleksi kaki berpengaruh terhadap tekanan darah $^{15,16,17,18,19,20,21}$ pada penderita hipertensi primer rentang usia 46 - $55(46,7 \%)^{15}$, pada penderita hipertensi sekunder ${ }^{16}$, terapi pijat refleksi kaki efektif menurunkan tekanan darah pada lansia. ${ }^{15}$ Hasil penelitian perbandingan menunjukkan pijat refleksi lebih efektif dibanding hipnoterapi. ${ }^{18}$

Adanya pengaruh kombinasi refleksi pijat kaki dan dzikir terhadap penurunan tekanan darah $^{22}$ dan tidak ada perbedaan efektivitas antara terapi pijat refleksi dan terapi Benson terhadap penurunan tekanan darah pada penderita hipertensi di Wilayah Kerja Puskesmas Hulonthalangi. ${ }^{23}$ Terapi Benson merupakan Teknik yang menggabungkan meditasi dengan relaksasi. ${ }^{24}$

Teori menyatakan bahwa risiko terjadinya hipertensi meningkat seiring dengan bertambahnya usia. Seseorang bertambah tua maka ia juga mengalami perubahan fisiologis, misalnya penurunan elastisitas arteri dan juga 
adanya kekakuan pembuluh darah, hal ini yang menyebabkan risiko hipertensi akan naik dengan bertambahnya umur. ${ }^{15}$ Hal tersebut terjadi karena adanya perubahan struktur pembuluh darah seperti penyempitan lumen, serta dinding pembuluh darah menjadi kaku dan elastisitasnya berkurang sehingga meningkatkan tekanan darah. ${ }^{25}$

Pijat refleksi adalah suatu praktik memijat titik-titik tertentu pada tangan dan kaki. Manfaat pijat refleksi untuk kesehatan sudah tidak perlu diragukan lagi. Salah satu khasiatnya yang paling populer adalah untuk mengurangi rasa sakit pada tubuh. Manfaat lainnya adalah mencegah berbagai penyakit, meningkatkan daya tahan tubuh, membantu mengatasi stress, meringankan gejala migrain, membantu penyembuhan penyakit kronis, dan mengurangi ketergantungan terhadap obatobatan. $^{26}$ Pijat refleksi juga mengurangi ketegangan, meningkatkan sirkulasi, dan mempromosikan fungsi alami dari tubuh melalui penerapan tekanan di berbagai titik-titik tertentu pada tubuh. ${ }^{9}$

Terapi pijat refleksi kaki dapat meningkatkan aliran darah. Kompresi pada otot merangsang aliran darah vena dalam jaringan subkutan dan mengakibatkan retensi darah menurun dalam pembuluh perifer dan peningkatan drainase getah bening. Selain itu juga dapat menyebabkan pelebaran arteri yang meningkatkan suplai darah ke daerah yang sedang dipijat, juga dapat meningkatkan pasokan darah dan meningkatkan efektivitas kontraksi otot serta membuang sisa metabolisme dari otot-otot sehingga membantu mengurangi ketegangan pada otot, merangsang relaksasi dan kenyamanan. ${ }^{26}$ Teknik relaksasi dapat menghilangkan stress yang selanjutnya menurunkan tekanan darah dan kecepatan nadi. Pemijatan pada titik-titik tertentu ditelapak kaki dapat menimbulkan relaksasi tubuh secara umum, dengan demikian memberi hasil positif bagi tekanan darah dan nadi. $^{28}$

Metode relaksasi seperti ini sangat baik untuk mengoptimalkan kembali fungsi organorgan tubuh yang sedang mengalami gangguan, membantu proses penyembuhan dengan cara alami, meningkatkan vitalitas tubuh, dan juga merefresh kesehatan tubuh secara keseluruhan. ${ }^{10}$ Hampir semua peneliti membuktikan bahwa pijat refleksi kaki menurunkan tekanan darah pada pasien hipertensi, sehingga pijat refleksi sangat baik untuk dijadikan intervensi keperawatan, baik di rumah sakit, klinik, maupun di masyarakat.

\section{KESIMPULAN}

Pijat refleksi kaki menurunkan tekanan darah pada pasien hipertensi. Tekanan darah yang turun terjadi pada sistolik dan diastolik, baik pada hipertensi primer, sekunder, serta pada lansia. Peneliti selanjutnya diharapkan dapat melakukan penelitian serupa, namun dengan menggunakan desain yang lebih kompleks seperti cohort, RCT dan dengan ukuran sampel yang besar, sehingga hasilnya lebih baik.Peneliti berikutnya juga diharapkan melakukan penelitian komparatif, seperti bekam dan dzikir.

\section{UCAPAN TERIMAKASIH}

Ucapan terimakasih penulis sampaikan kepada pimpinan dan staf klinik Klinik ATFG-8 Palembang yang telah memberikan izin dan kesempatan untuk melakukan penelitian. Kepada Direktur dan civitas akademika Poltekkes Palembang ucapan terima kasih yang tak terhingga kami haturkan.

\section{DAFTAR PUSTAKA}

1. Sari, Y. N. Berdamai dengan Hipertensi. Jakarta: Bumi Medika. 2017

2. Tanto, C. Kapita Selekta Kedokteran. Jakarta: Media Aesculapius. 2014.

3. Widyanto, F. C., \& Triwibowo, C. Trend Disease "Trend Penyakit Saat Ini". Jakarta: TIM. 2013.

4. Wade, C. Mengatasi Hipertensi. Bandung: Nuansa Cendekia. 2016

5. Ardiansyah, M. Medikal Bedah Untuk Mahasiswa. Jogjakarta: DIVA Press. 2012

6. Kemenkes RI. Hipertensi. Jakarta: Pusat Data dan Informasi Kementerian Kesehatan RI. 2014.

7. Khoirin, \& Rosita, M. Faktor-faktor yang berhubungan dengan kepatuhan diet pada pasien hipertensi di Puskesmas Pakjo Palembang Tahun 2018. Babul Ilmi_Jurnal Ilmiah Multi Science Kesehatan 2018; 8(2); $76-89$

8. Widharto. Bahaya Hipertensi. Jakarta: PT. Sunda Kelapa Pustaka. 2009.

9. Alviani, P. Pijat Refleksi Pijatan Tepat, Tubuh Sehat. Yogyakarta: Pustaka Baru Press. 2015.

10. Amir, S., \& Rokimun. Wow Fakta! Sembuh Alami Untuk Berbagai Penyakit Berbahaya. Jakarta: Dunia Sehat. 2016

11. Rahimsyah. Pengobatan Cara Herbal dan Pijat Refleksi Solusi Hidup Sehat dengan Alami. Surakarta : PT Widya Duta Grafika. 2011

12. J.E.M.McCullough,S.D.Liddle,M.Sinclair,C.Close, andC.M.Hughes. ReviewArticle The Physiological and Biochemical Outcomes Associated with a Reflexology Treatment: A Systematic Review. 2014. Evidence-Based Complementary and 
Alternative Medicine Volume 2014, Article ID 502123, 16 pages

13. J. Jones, P. Thomson, W. Lauder, K. Howie, and S. J. Leslie, "Reflexology has an acute (immediate) haemodynamic effect in healthy volunteers: adouble-blindrandomisedcontrolledtrial 2012. Complementary Therapies in Clinical Practice, vol.18, pp.204-211,2012

14. Nursalam. Metodelogi Penelitian Ilmu Keperawatan. 2016. Jakarta: Salemba.

15. Rezky, RA., Hasneli, Y, Hasanah, O. Pengaruh Terapi Pijat Refleksi Kaki Terhadap Tekanan Darah Pada Penderita Hipertensi Primer. 2015. JOM. 2 (2): $1454-1462$.

16. Aswatik. Pengaruh Pijat Refleksi Kaki Terhadap Tekanan Darah Pada Penderita Hipertensi Sekunder Di Dusun Blimbing Karangrejek Wonosari Gunungkidul Tahun 2016. 2016. Skripsi thesis, STIKES Bethesda Yakkum.

17. Hartutik, S., \& Suratih, K. Pengaruh Terapi Pijat Refleksi Kaki Terhadap Tekanan Darah Pada Penderita Hipertensi Primer. 2017. Jurnal GASTER. XV (2); 132 - 146.

18. Nugroho, AA., Asrin, \& Sarwono. Efektifitas Pijat Refleksi Kaki Dan Hipnoterapi Terhadap penurunan Tekanan Darah Pada Pasien Hipertensi. 2012 Jurnal Ilmiah Kesehatan Keperawatan, 8 (2); $57-63$.

19. Arianto, A., Prastiwi, S., \& Sutriningsih, A. Pengaruh Terapi Pijat Refleksi Telapak Kaki Terhadap Perubahan Tekanan Darah Pada Penderita Hipertensi. 2018, Nursing News: Jurnal Ilmiah Keperawatan 3(1); $584-594$

20. Marisna, D., Budiharto, I., \& Sukarni. Pengaruh Terapi Pijat Refleksi Kaki Terhadap Perubahan Tekanan Darah Pada Penderita Hipertensi Wilayah Kerja Puskesmas Kampung Dalam Kecamatan Pontianak Timur. Pontianak: Universitas Tanjungpura, Laporan Penelitian, http://jurnal.untan.ac.id/index.php/jmkeperawatanF $\mathrm{K} /$ article/view/22004/17640, download 29 Desember
21. Zunaidi, A., Nurhayati, S., \& Prihatin, T. W. Pengaruh Pijat Refleksi Terhadap Tekanan Darah Pada Penderita Hipertensi Di Klinik Sehat Hasta Therapetika Tugurejo Semarang. Sekolah Tinggi Karya Husada Semarang. 2014.

22. Pratiwi, Satria, I., \& Praja, A. 2017. Analisis Klinik Praktik Keperawatan pada Pasien Hipertensi dengan Intervensi Inovasi Kombinasi Pijat Refleksi Pijat Kaki dan Dzikir Terhadap Penurunan Tekanan Darah di Ruang Instalasi Gawat Darurat RSUD Abdul Wahab Sjahranie Samarinda Tahun 2017, https://dspace.umkt.ac.id//handle/463.2017/314, download 29 Desember 2019.

23. Ratna, R., \& Aswad, A. Efektivitas Terapi Pijat Refleksi Dan Terapi Benson Terhadap Penurunan Tekanan Darah Pada Penderita Hipertensi. 2019. Jambura Health and Sport Journal. 1(1); 33 - 40.

24. Benson \& Proctor. Dasar- dasar respon relaksasi. Edisi 1. Alihurhasan. Penerbit Kaifa: Bandung. 2000

25. Sherwood, L. Fisiologi manusia sel ke sistem. Jakarta: EGC. 2011

26. Wahyuni, S. Pijat refleksi untuk kesehatan. Jakarta Timur: Dunia Sehat. 2014

27. Chanif \& Khoiriyah. Efektifitas Terapi Pijat Refleksi Kaki Terhadap Tekanan Darah Pada Pasien Hipertensi. 2016. The 4th ISSN 2407-9189 Univesity Research Coloquium 2016214 - 221, https://publikasiilmiah.ums.ac.id/bitstream/handle/ 11617/7798/MIPA\%20DAN\%20KESEHATAN_2 8.pdf? sequence $=1 \&$ is Allowed $=y, \quad$ download tanggal 29 Desember 2019.

28. Embong,N. H., Soh,Y. C., Ming,L. C., \& Wong T. W. Revisiting reflexology: Concept, evidence, current practice, and practitioner training. J Tradit omplement Med. 2015; 5(4): 197-206.doi: 10.1016/j.jtcme.2015.08.008 